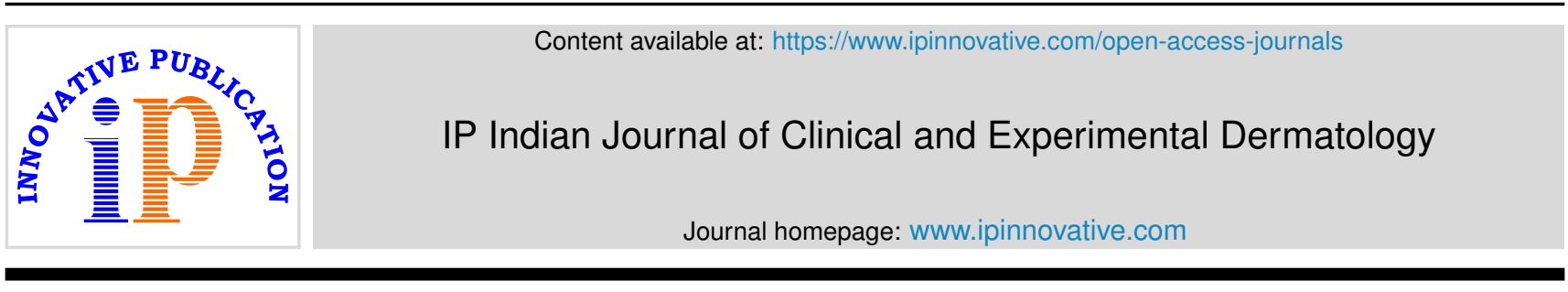

Original Research Article

\title{
Evaluation of safety and efficacy of hydrogen peroxide stabilized cream for treatment of mild to moderate acne vulgaris in comparison with benzoyl peroxide gel - double blinded, randomized control study
}

\author{
Meetesh Agrawal $^{1}$, Animesh Saxena ${ }^{1}$,*, Aditi Tripathi ${ }^{2}$, Vivek Kumar Dey ${ }^{1}$, \\ Shalini Kushwaha ${ }^{1}$, Prachi Shrivastava ${ }^{1}$, Sonal Hemnani ${ }^{1}$ \\ ${ }^{1}$ Dept. of Dermatology, People's College of Medical Science \& Research Centre, Bhopal, Madhya Pradesh, India \\ ${ }^{2}$ Kanak Skin Care ( A unit of R.K.O.T.C), Bikaner, Rajasthan, India
}

\section{A R T I C L E I N F O}

\section{Article history:}

Received 15-07-2020

Accepted 31-07-2020

Available online 03-10-2020

\section{Keywords:}

Acnevulgaris

Benzoyl peroxide Hydrogen peroxide

\begin{abstract}
A B S T R A C T
Acne is defined as a chronic inflammatory disorder of the pilosebaceous unit, which is characterized by comedones, seborrhea, pustules, nodules, pseudocysts and scarring, in some cases. Benzoyl peroxide (BP) is a time tasted molecule in the management of acne. In current study we have tried to compare efficacy of benzoyl peroxide with hydrogen peroxide (HP) in acne vulgaris (AV).

Aims : To study efficacy and local tolerability of BP and HP in Acne Vulgaris treatment. To compare the efficacy and local tolerability of BP gel and HP cream in a Acne Vulgaris (GRADE 1 AND 2) treatment. Materials and Methods: A double blinded, randomised control study for the duration of 18 months was carried out in which a total of 150 patients of acne vulgaris (Grade $1 \& 2$ ) between the age of 13-30 years of both genders were recruited, which were divided in two groups, with one group treated with benzoyl peroxide gel $2.5 \%$ and second group being treated with hydrogen peroxide cream. All the data analysis was done using IBM SPSS ver. 20 software.

Results: Both drugs were found to be equally efficacious in reducing acne lesions. Hydrogen peroxide group experienced less side-effects as compared to benzoyl peroxide group.

Conclusion: Hydrogen peroxide and benzoyl peroxide are equally efficacious.

Key Messages: In acne grade one and two benzoyl peroxide and hydrogen peroxide are equally efficacious though hydrogen peroxide has less adverse effect.

(C) 2020 Published by Innovative Publication. This is an open access article under the CC BY-NC license (https://creativecommons.org/licenses/by-nc/4.0/)
\end{abstract}

\section{Introduction}

Acne is the commonest dermatological disorder affecting $85 \%$ of individuals in age group of 12 and 24 years. ${ }^{1}$ It is estimated that in age group of 25 to 40 years $41 \%$ of people suffer from acne lesions for at least 3 to 4 months per year. ${ }^{2}$

Current treatments includeoral medicationsand topical that counteract sebum production, P. acne colonization and inflammation. ${ }^{3}$ Widely usedtopical compounds are benzoyl peroxide ${ }^{4}$ (BP), antibiotics ${ }^{5}$ and retinoids ${ }^{6}$ while antibiotics like tetracyclines, azithromycin, ${ }^{7}$ retinol derivatives like isotretinoin ${ }^{8}$ and oral contraceptives

\footnotetext{
* Corresponding author.

E-mail address: animesh7891@ gmail.com (A. Saxena).
}

likecyproterone acetate are commonly used oral agents. ${ }^{9}$

According to the first global alliance therapeutic guidelines of acne (2003), (BP) was considered the first drug of choice for treatment of mild and moderate AV. ${ }^{10}$ This statement was substantially confirmed in the second global alliance publication in 2009. ${ }^{11}$

Recently, a new formulation of Hydrogen peroxide $1 \%(\mathrm{HP})$ in stabilised cream became available in Indian market. The study product contained hydrogen peroxide $\left(\mathrm{H}_{2} \mathrm{O}_{2}\right)$, which is an odourless and colourless liquid. ${ }^{12}$ HP is very unstableand disintegrate upon light exposure, but dissolves easily in water. ${ }^{13}$ The stabilization of HP in the dermo-cosmetic formulations was extremely difficult, which required addition of stabilizing agents and 
aspecialized packaging. ${ }^{14}$

In present study we tried to evaluate the safety and efficacy of HP stabilized cream for treatment of mild to moderate $\mathrm{AV}$ in comparison with $\mathrm{BP}$ gel.

\section{Materials and Methods}

We conducted a double blinded, randomised control study for the duration of 18 months from November 2016 to May 2018.

Sample size was calculated by using the formula $4 \mathrm{pq} / \mathrm{D}^{2}$ where $\mathrm{p}$ is prevalence and $\mathrm{q}$ is $10-\mathrm{p}$ and $\mathrm{D}^{2 i s}$ allowable error. Simple random sampling method was used for randomisation. A total of 150 consenting patients of acne vulgaris (Grade $1 \& 2$ ) between the age of 13-30 years of both genders were recruited during this time period and minors' consent was taken from parents.

After ethical approval data collection was started and patients were divided randomly in two groups, with one group treated with benzoyl peroxide gel $2.5 \%$ and second group being treated with hydrogen peroxide cream, having 75 patients in each group respectively. Both investigator and the patient were blinded to the type of treatment.

Efficacy were assessed at each visit (baseline, week 4 , and week 8 ) by counting total lesion (TL), IL, NIL and by taking photographs at baseline, 4 week, 8 week . At 8 week, a clinical global assessment, in comparison with baseline were performed using qualitative score:-0 = worsening, $1=$ no improvement, $2=$ mild improvement, $3=$ moderate improvement, $4=$ good improvement, $5=$ very good improvement. Tolerability were assessed at 4 and 8 week on $0-3$ qualitative scale $0=$ poor tolerability, $1=$ mild tolerability, $2=$ moderate tolerability, $3=$ good tolerability. Side effects like erythema, dryness, burning sensation and itching were $b$ evaluated using $0-3$ qualitative score $0=$ none, $1=$ mild, $2=$ moderate, $3=$ severe

To assure the blinded characteristics of the trial, the observer was unaware of the treatment allocation performed. The observer only took photgraphs and calculated total number of lesion and assessed tolerability on the basis of pre- structured performa at baseline and at each visit.

Statistical Analysis

All the data analysis was done using IBM SPSS ver. 20 software. Frequency distribution and cross tabulation was used to prepare tables. Microsoft word 2010 was used to prepare graphs. Different study variables were compared using Chi square test. Value of less than 0.05 was considered statistically significant.

\section{Result}

Majority of the patients were in the age group of 16-20 years [65 (43.3\%)] followed by 21-25 years [39 (26\%)]. Majority of the patients were of young age ( $<25$ years). Most of the patients were female [91 (60.7\%)].

Majority of the patients had acne grade 2 [81 (54\%)] followed by acne grade 1 [69(46\%)].

Maximum patients had acne on the cheek [57 (38\%)] followed by forehead, Chin and Cheek.

Comparing inflammatory lesions, non inflammatory lesions and total lesions at follow up with baseline revealed that both the treatment were equally efficacious in reducing the inflammatory lesions, non inflammatory lesions and total lesions at the end of $4^{\text {th }}$ and $8^{\text {th }}$ week $(\mathrm{p}>0.05)$. (Figures 1, 2 and 3).

In present study comparing the tolerability of both the drugs revealed that erythema was significantly higher with benzoyl peroxide ( 7 out of 8 cases) as compared to hydrogen peroxide (1 out of 8 cases). Similarly, Pruritus and Burning Sensation were significantly higher among the patients using benzoyl peroxide ( 9 out of 10 cases) and ( 10 out of 11 cases)as compared to hydrogen peroxide (1 out of 10 cases) and (1 out of 11 cases) respectively. (Figure 4)

Comparing both treatment for total lesions after $8^{\text {th }}$ week of treatment between grade 1 and 2 of acne, we found both the drug equivalent. That means both the drugs are equally efficacious for grade 1 and grade 2 of acne ( $\mathrm{P}$ value $>0.05$ ).

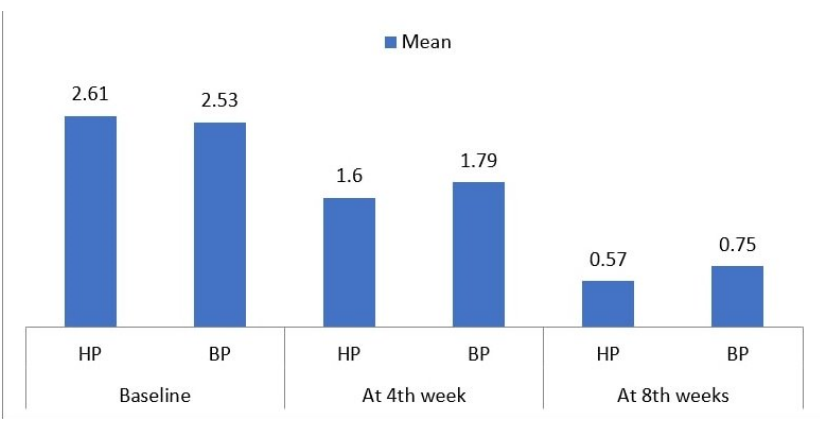

Fig. 1: Comparing inflammatory lesions at follow up with baseline

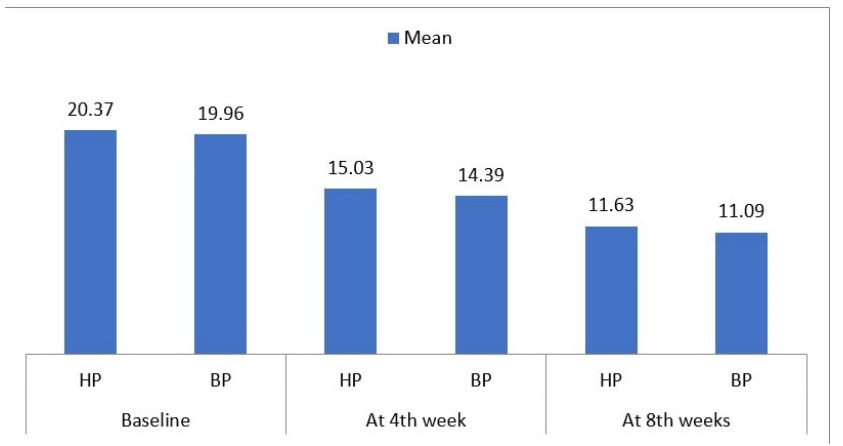

Fig. 2: Comparing non- inflammatory lesions at follow up with baseline 


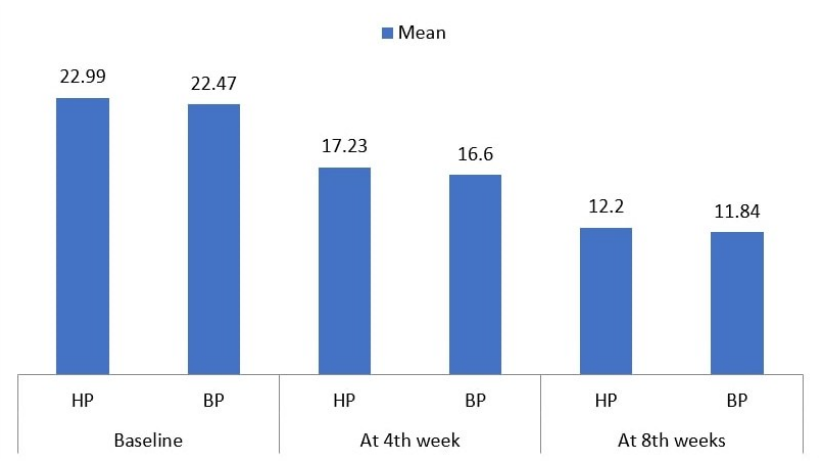

Fig. 3: Comparing total lesions at follow up with baseline

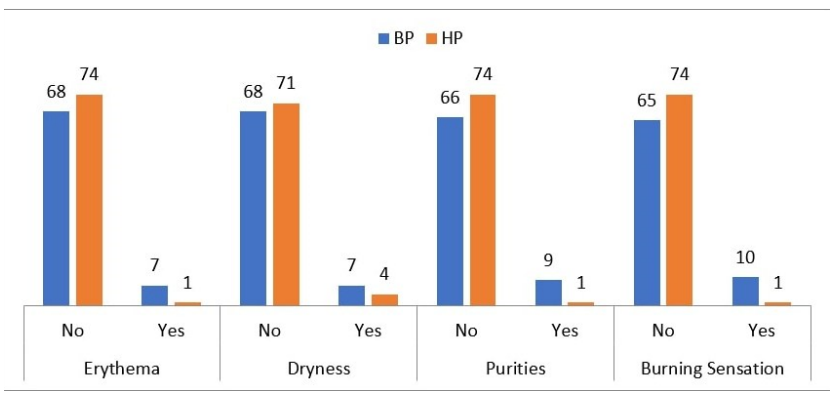

Fig. 4: Comparing tolerability of the drug

\section{Discussion}

Acne is the most common skin disorder of pilosebaceous unit which is characterized by excessive sebum production, redness and scaling of skin along with comedones (open and closed), papules, pustules, nodules and its sequel scarring in some patients. ${ }^{15}$

In present study we found that $1 \% \mathrm{HP}$ was effective in mild to moderate acne. However reports have shown that products containing 3\% HP have can cause local skin discoloration and are used for skin disinfection.

In present study majority of the patients were in the age group of $16-20$ years $(43.3 \%)$ followed by 21 25 years (26\%). That means majority of the patients were of young age ( $<25$ years). Maximum patients were female [91 (60.7\%)]. In the present study, out of the 150 patients enrolled, 13 were lost to follow up, which might have been due to patients coming from peripheral areas, noncompliance with the inclusion criteria, not satisfied with the treatment and longer follow up. Majority of the patients had acne grade 2 [81 (54\%)] followed by acne grade 1 [69 $(46 \%)]$.

Veraldi et al evaluated the tolerability and efficacy of a novel HP-based regimen versus a BP-based regimen in 120 patients with mild to moderate acne and the intergroup comparison demonstrated that the mean Global Acne Grading System (GAGS) overall scores (combining time points) didn't differ significantly in between both the treatments over time. $(\mathrm{p}=0.9922){ }^{16}$

In present study, maximum patients had acne on the cheek [57 (38\%)] followed by Fore Head, Chin, Cheek [30 (20\%)] and Neck, Chin [29 (19.3\%)]. Veraldi et al studied 120 patients and found that in all patients, the face was involved and in one patient, the back was also involved. ${ }^{16}$

Comparing inflammatory lesions at follow up with baseline revealed that both the treatment were equally efficacious in reducing the inflammatory lesions at the end of $4^{\text {th }}$ and $8^{\text {th }}$ week ( $\left.\mathrm{p}>0.05\right)$. In present study noninflammatory and total lesions at follow up revealed that both the treatment were equally efficacious in reducing the non-inflammatory lesions at the end of $4^{\text {th }}$ and $8^{\text {th }}$ week $(\mathrm{p}>0.05)$

In a similar study by Kisiel et al showed that a significant reduction in acne lesions $(\mathrm{P}=0.0003)$ and number of pustular lesions $(\mathrm{P}=0.002)$ which means a trend toward reduction of number of comedones and papules was also observed among patients using $\mathrm{HP}^{2}$. Muizzuddin et $\mathrm{al}^{17}$ reported that in a six-week clinical study, a 56\% reduction in total number of inflammatory lesions and $45 \%$ reduction in noninflammatory lesions.

In a recent study by Muizzuddin et al, ${ }^{17}$ published in 2013, a new HP formulation using the enzyme glucose oxidase and glucose was used. This new system was stable and the formulation was effective in reduction of number of inflammatory lesions by $68 \%$ and reduction in acne lesion size by $61 \%$ within the span of the study.

In present study comparing the tolerability of both the drugs revealed that erythema was significantly higher with BP ( 7 out of 8 cases) as compared to HP (1 out of 8 cases). Similarly, pruritus and burning sensation was significantly higher among the patients using BP (9 out of 10 cases) as compared to HP (10 out of 11 cases). Contrary to present study Veraldi et al compared novel HP-based regimen versus a BP-based regimen in 120 patients and found that no significant adverse events were reported or observed in either treatment arm. ${ }^{16}$

In current study assessment method was used as followed by Capizzi et al in their study, where they evaluated tolerability and the efficacy of combination therapy with HP cream and adapalene $0.1 \%$ gel and compared it with combination of BP $4 \%$ cream and adapalene $0.1 \%$ gel in treatment of $\mathrm{AV}$, they reported that combination of adapalene and HP cream is an effective topical regimen in mild to moderate $\mathrm{AV}$ and has a better tolerability profile in comparison with the combination of BP and adapalene.

In agreement to present study Kisiel et al evaluated the safety and the anti-acne efficacy of a point-gel containing $2 \% \mathrm{H} 2 \mathrm{O} 2$ and salicylic acid $(0.54 \%)$, phytic acid (1\%), D-panthenol (1\%) and vitamin PP (0.012\%) and reported no skin side effects (including pruritus, skin redness or dryness). ${ }^{2}$ 
In present study both the treatment were equally efficacious in reducing acne $(\mathrm{p}=0.177)$ Veraldi et al evaluated the efficacy and tolerability of a novel HP-based regimen versus a BP-based regimen in 120 patients with mild to moderate acne and reported that there was no significant difference in efficacy between the two acne regimens. ${ }^{16}$ Study done by Milani et al ${ }^{18}$ who studied the role of $1 \% \mathrm{HP}$ cream on 60 patients and reported that HP was as effective as BP in reducing both inflammatory and non-inflammatory lesions. However, $1 \%$ HP cream had a better tolerability profile. ${ }^{18} \mathrm{In}$ a similar study by Capizzi et al ${ }^{19}$ tolerability and efficacy of $1 \% \mathrm{HP}$ cream and $0.1 \%$ adapalene gel combination was compared with the $4 \%$ BP cream and $0.1 \%$ adapalene gel combination in 52 patients and it was reported that a significantly greater reduction in noninflammatory lesions was observed in the HP/adapalene group.

The mechanism by which HP acts is similar to the mechanism of BP. ${ }^{20} \mathrm{HP}$ reduces Propionibacterium acnes colonization. ${ }^{18}$ A theoretic future of topical HP may be represented by its use in atrophic acne scars. A report demonstrated that free oxygen radicals can stimulate as well as inhibit cultured human fibroblasts proliferation, also that fibroblasts release superoxide free radicals in concentrations that can stimulate proliferation, a finding confirmed by a dose-dependent inhibition of proliferation by free radical scavengers. Thus, providing a fast and specific trigger for fibroblast proliferation. However, sustained stimulation might result in fibrosis. ${ }^{21}$

A study by Fabbrocini and Panariello showed efficacy of a local applicant containing 3\% HP, $1.5 \%$ salicylic acid and $4 \%$ D-panthenol in the management of mild to moderate acne vulgaris. The product was applied on the whole skin surface for 60 days and was shown to have high efficacy as compared to previous version of product containing higher HP and lower salicylic acid concentrations (4 and 0.5\%, respectively). ${ }^{22}$

In present study both the drugs had equal efficacy for both the acne grades in terms of total lesions after 8th weeks of therapy. Tolerability was similar for grade 1 acne whereas HP was more tolerable in terms of Erythema and Burning Sensation as compared to BP. Similar results were reported by the study done by Capizzi et al, ${ }^{19}$ by Milani et al ${ }^{18}$ and Veraldi et al. ${ }^{16}$ Both HP and BP are widely used for the treatment of Acne vulgaris grade 1 and 2, however there is paucity of data related to their comparison with each other in terms of their efficacy and tolerability, therefore the present study was done.

Low number of participants in each group is limitation of the study.

\section{Source of Funding}

None.

\section{Conflict of Interest}

None.

\section{References}

1. Bergfeld WF. Topical retinoids in the management of acne vulgaris. $J$ Drug Dev Clin. 1996;8:151-60.

2. Kisiel K, Dębowska R, Dzilińska K, Radzikowska A, PasikowskaPiwko M, Rogiewicz K, et al. New H2O2 dermocosmetic in acne skin care. Our Dermatol Online. 2018;9(e):e3.1-6.

3. Simpson NB, Cunliffe WJ. Disorders of the pilosebaceous glands. In: Burns T, Cox N, Breathnach S, Christopher GC, editors. Rook's Textbook of Dermatology. vol. 43. London: Blackwell Publishing; 2004.

4. Mills OH, Kligman AM, Pochi P, Comite H. Comparing 2.5\%, 5\%, and $10 \%$ Benzoyl Peroxide on Inflammatory Acne Vulgaris. Int $J$ Dermatol. 1986;25(10):664-7.

5. Eady EA, Cove JH, Joanes DN, Cunliffe WJ. Topical antibiotics for the treatment of acne vulgaris: A critical evaluation of the literature on their clinical benefit and comparative efficacy. J Dermatol Treat. 1990;1(4):215-26.

6. Jain S. Topicaltretion or adapalene in acne vulgaris: An overview. $J$ Dermatol Treat. 2004;15:200-7.

7. Webster GF. Acne vulgaris and rosacea: Evaluation and management. Clin Cornerstone. 2001;4(1):15-22.

8. Acne vulgaris. In: Drugs used in Skin Diseases: WHO Model Prescribing Information, World Health Organization. Geneva; 1997. p. 65 .

9. Leyden JJ. A review of the use of combination therapies for the treatment of acne vulgaris. J Am Acad Dermatol. 2003;49:211-7.

10. Gollnick H, Cunliffe W. Management of acne: a report from a global alliance to improve outcomes in acne. J Am Acad Dermatol. 2003;49(1):1-37.

11. Thiboutot D, Gollnick H. New insights into the management of acne: an update from the Global Alliance to improve outcomes in acne group. J Am Acad Dermatol. 2009;60(5):1-50.

12. Milani M. Efficacy and safety of hydrogen peroxide cream alone or in combination with salicilyc foam in the treatment of mild-to-moderate acne. J Am Acad Dermatol. 2004;50(3):1-4.

13. Ricci F, Masini F, Fossati B, Frascione P, Waure CD, Capizzi R, et al. Combination therapy with hydrogen peroxide $(4 \%)$, salicylic acid $(0.5 \%)$ and D-panthenol (4\%): efficacy and skyn tolerability in common acne vulgaris during sun exposure period. Eur Rev Med Pharmacol Sci. 2016;19:232-6.

14. Kisiel K, Dębowska R, Pasikowska M, Vincent C, Ciecińska C, Chełstowska-Paździorko J, et al Ocenaskutecznociibezpieczeństwastosowaniadermokosmetyków do myciaciałaiwłosów u dzieci $\mathrm{z}$ atopowymzapaleniemskóry. Dermatol Dziec. 2016;6:42-5.

15. Kataria U, Chhillar D. Etiopathogenesis and its management . Int Arch Integr Med. 2015;2:225-31.

16. Veraldi S, Micali G, Berardesca E, Sinagrajl F, Guanziroli E. Results of a Multicenter, Randomized, Controlled Trial of a Hydrogen Peroxide-based Kit versus a Benzoyl Peroxide-based Kit in Mild-tomoderate Acne. J Clin Aesthet Dermatol. 2016;9(10):50-4.

17. Muizzuddin N, Schnittger S, Maher W. Enzymatically generated hydrogen peroxide reduces the number of acne lesions in acne vulgaris. J Cosmet Sci. 2013;64:1-8.

18. Milani M, Bigardi A, Zavattarelli M. Efficacy and safety of stabilized hydrogen peroxide cream $\left(\right.$ Crystacide $\left.^{\circledR}\right)$ in mil-tomoderate acne vulgaris: a randomized, controlled trial versus benzoyl peroxide gel. Curr Med Res Opin. 2003;19:135-8.

19. Capizzi R, Landi F, Milani M, Amerio P. Skin tolerability and efficacy of combination therapy with hydrogen peroxide stabilized cream and adapalene gel in comparison with benzoyl peroxide cream and adapalene gel in common acne. A randomized, investigator-masked, controlled trial. Br J Dermatol. 2004;151(2):481-4. 
20. Haustein UF, Ziegler B. Treatment of acne vulgaris with hydrogen peroxide emulsion (L/W). Dermatol Monatsschr. 1987;173:323-7.

21. Murrell GAC, Francis MJO, Bromley L. Modulation of fibroblast proliferation by oxygen free radicals. Biochemical $J$. 1990;265(3):659-65.

22. Fabbrocini G, Panariello L. Efficacy and tolerability of a topical gel containing 3\% hydrogen peroxide, 1,5\% salicylic acid and 4\% Dpanthenol in the treatment of mild-moderate acne. G Ital Dermatol Venereol. 2016;151:287-91.

\section{Author biography}

Meetesh Agrawal Associate Professor

Animesh Saxena Assistant Professor
Aditi Tripathi Director

Vivek Kumar Dey Professor and HOD

Shalini Kushwaha Junior Resident

Prachi Shrivastava Assistant Professor

Sonal Hemnani Junior Resident

Cite this article: Agrawal M, Saxena A, Tripathi A, Dey VK,

Kushwaha S, Shrivastava P, Hemnani S. Evaluation of safety and

efficacy of hydrogen peroxide stabilized cream for treatment of mild to moderate acne vulgaris in comparison with benzoyl peroxide gel

- double blinded, randomized control study. IP Indian J Clin Exp

Dermatol 2020;6(3):217-221. 